\title{
Optimizing New Product Concept Selection Decisions Considering Life Cycle Design Attributes
}

\author{
Alireza Yazdankhah and Mojgan Fathalipourbonab
}

\begin{abstract}
Concept selection is one of the most important phases in product development process. In this process, product life cycle issues need be taken into consideration. However, effective strategies for considering life cycle issues in concept selection have not been fully explored in the existing literature. In this paper, we discuss the importance of considering product life cycle design attributes in concept selection process by investigating the current literature regarding product design and life cycle issues. Then a fuzzy based decision-making and optimization framework is proposed to select the best alternative concept considering life cycle design attributes. Finally a numerical example is presented to better illustration of proposed methodology.
\end{abstract}

Index Terms - Concept selection, product life cycle attributes, fuzzy AHP, goal programming.

\section{INTRODUCTION}

In current competitive market, companies need to design and develop new products or redesign their existing products. In addition to competitive economic situation, changing customer needs the emergence of new markets and new technologies require very fast product development process. Concept selection is one of early stages in product development in which proposed concept are evaluated to select the best concept that best fulfill the decision making criteria. Concept selection is the most crucial phase of the product development process due to its influence on all subsequent phases with regards to cost, quality and performance of the end-product. The importance of design evaluation is apparent, because a poor selection of a design concept can rarely be compensated at later design stages and incurs a great redesign expense [1]. It has been recognized that nearly $75 \%$ of product life-cycle cost is committed by the end of conceptual design [2].

For an enterprise considering the launch of a new product, it is very important to have a better image of its product life cycle. During this selection process at the early design stage, designers should consider not only the product functionality needed, but also other criteria including life-cycle issues, such as manufacturability, ease of assembly, reliability, maintainability [3]. This will help effective resource management and reduce risk of product launch.

Although many models proposed in the literature to deal

Manuscript received December 20, 2013; revised February 11, 2014

Alireza Yazdankhah is with the Department of Industrial Engineering, Islamic Azad University-Bonab Branch, Bonab, Iran (e-mail: alirezayazdankhah1@gmail.com).

Mojgan Fathalipourbonab is with the Arkan Trailer Bonab, Bonab, Iran (e-mail: mojgan_fathalipoor@yahoo.com). with concept selection problem or product life cycle, little or no attention has devoted to consider their integration in selecting proper concept at early stages of product development. In this paper we are trying to fill this gap. In Section II, an overview of concept selection problem modeling techniques is given. Next, an overview of product design process and life cycle modeling techniques is presented. In Section III, an overview and background of related techniques used in proposed methodology will be given. Proposed methodology will be presented in Section IV. To better illustration of using proposed methodology, an illustrative example is presented in Section V. Finally summary and conclusion is given.

\section{LITERATURE REVIEW}

\section{A. Concept Selection Problem}

In the literature, many models and techniques have been applied to concept selection in different fields. Pugh [4] developed a fast and simple graphical method which utilizes a matrix with columns (concepts) and rows (decision criteria). This method provides an insight to the concepts that are decidedly better than the others. However, this method does not allow for criteria to be given weights, nor does it allow for coupled decisions.

Fung et al. proposed a quality-engineering-based conceptual design approach which integrates the use of Quality Function Deployment (QFD), Morphological Matrix Analysis (MMA), Multi-Attribute Decision Making (MADM) techniques and Stochastic Optimization Models (SOMs). Although methods based on decision matrices provide a useful insight into qualitative preferences over alternatives graphically, they are unable to take into account relative importance and the impact of coupled decisions [5].

Marsh [6] developed a more specific AHP method directed for design decision-making. This approach also uses pairwise comparisons to determine a weight vector for all the alternatives. King and Sivaloganathan [7] proposed a method that considers the impact of coupled decisions. The problem is decomposed into two parts; in the first part, all concepts are evaluated against functional requirements, while in the second part, all concepts are evaluated for their compatibility with one another. The scores from these two evaluations are multiplied, and the concept combination with the highest score is selected. Using this approach might lead to unnecessary elimination of concepts [8].

Chang [9] proposed a two stage fuzzy extent analysis approach to accommodate fuzzy logic into AHP defined as fuzzy AHP (FAHP). In the first stage, Triangular Fuzzy 
Numbers (TFN) are used for pairwise comparisons of FAHP. In the second stage, a synthetic extent value of the pairwise comparisons is introduced, and by applying the principle of comparison of fuzzy numbers, the weight vectors with respect to each element under a certain criterion can be obtained to reach a decision.

Ayag [10] suggested a FAHP based simulation approach carried out in four steps. In the first step, TFNs are used to indicate the relative strength of each pair of elements in the same hierarchy. Secondly, using TFNs via pairwise comparisons, a fuzzy judgment matrix is constructed. In the third step, fuzzy Eigen values are calculated using the a-cut method which incorporates the decisions-maker's confidence over his/her judgments. Finally, the priority weight of each alternative is obtained by multiplying the matrix of evaluation ratings by the vector of attribute weights and summing over all the attributes. This method requires knowledge of simulation programming and fuzzy mathematics which may be beyond the scope of a typical design engineer, and gathering data and running simulations can be a tedious and time consuming process.

\section{B. Product Design Process and Life Cycle Modeling}

Different authors have proposed methodologies dealing with life cycle modeling and product design. These methods differ in the goal for modeling, the scope of life cycle analyzed, type of models used, the phase(s) of design they support, and the treatment of uncertainty. Fitch and Cooper Fitch and Cooper [11] have presented methodology called Life-cycle modeling for design (LCMD) for assessing the life-cycle impacts for a complex product with many individual components starting from initial design phases when few design specifications have been made. Their methodology combines life-cycle assessment (LCA) with probabilistic design methods in a way that forecasts attributes of possible final designs yet reduces information needs.

Umeda [12] proposed a life-cycle simulation model that consists of a life-cycle simulator, an optimizer, a model editor, and knowledge bases. The simulation system evaluates product life cycles from an integrated view of environmental consciousness and economic profitability and optimizes the life cycles. Regnier and Hoffman [13] discussed sources of uncertainty in environmental performance measurement using Motorola's Green Design Advisor environmental scoring software. They proposed a probabilistic method for measuring both data and model uncertainty. Then by using Monte Carlo simulation, this model was applied to two Motorola product designs to generate probability distributions for the scores. Eisenhard [14] used neural network to train on product attributes and environmental impact data from pre-existing lifecycle assessment studies. The product design team queries the trained artificial intelligence model with new high-level product attribute data to quickly obtain an approximate impact assessment for a new product concept.

Azapagic and Clift [15] proposed the use of multi-objective system optimization in LCA as a tool for identifying and evaluating the best possible options for environmental management of the product system. Anand and Wani [16] mentioned and described some relevant attributes for life cycle design as following:

Design for Performance: Identify the customer requirements, analysis of actual need, concept hunt, and transformation of customer requirements into design specifications, identification of critical components and functions, development of design concepts, feasibility of design concepts.

Design for Manufacturing: Easy to manufacture, less emission of toxic gases, ease of assembly/disassembly, use of simple and standard components and assemblies, minimum labor/machine costs, minimum material wastage, ease of disposal/recycling.

Design for Marketing: Long shelf life, ease of installation and commissioning, ease of transport, operation/handling, safety, durability, low energy requirements, less number of failures.

Design for Maintenance: Easy opening/fastening of parts and components of various assemblies and subassemblies, reduced number of components and assemblies, compatibility between mating components when replacing a faulty item/component, high proficiency in carrying out maintenance work and diagnosis, hazard free environment for maintenance work.

Design for Safety: Operational techniques, minimum number of failures, higher availability, low breakdowns, perform desired functions, higher safety, minimum emission of toxic wastes, increased functional life.

Design for Environment: Minimum emission of toxic substances to environment, ease of disposal/recycling, minimum waste of materials and energy, minimum energy consumption, extended life of lubricants, materials and components, ease of assembly/disassembly, surface coatings.

Design for Disposal: Ease to assemble and disassemble, eco-friendly, minimum cost, easy to machine, conservation of energy (retention of quality/strength), material conservation, recycling of materials.

\section{BACKGROUND}

\section{A. Fuzzy Logic system}

In dealing with a decision process, the decision maker is often faced with multiple alternatives and uncertainties. In other words, natural language to express perception or judgment is always subjective, uncertain or vague. To resolve the vagueness, ambiguity and subjectivity of human judgment, fuzzy sets theory [17] was introduced to express the linguistic terms in decision making (DM) process. Bellman and Zadeh [18] developed fuzzy multi-criteria decision making (FMCDM) methodology to resolve the lack of precision in assigning importance weights of criteria and the ratings of alternatives regarding evaluation criteria. A fuzzy set is a set of objects in which there is no clear-cut or predefined boundary between the objects that are or are not members of the set. The key concept behind this definition is that of "membership": any object may be a member of a set "to some degree"; and a logical proposition may hold true "to some degree". Each element in a set is associated with a value indicating to what degree the element is a member of the set.

\section{B. Analytic Hierarchy Process (AHP)}

According to Saaty [19], AHP is a theory of measurement 
through pairwise comparisons and relies on the judgments of experts to derive priority scales. It is these scales that measure intangibles in relative terms. The comparisons are made using a scale of absolute judgments that represents how much more an element dominates another with respect to a given attribute. The judgments may be inconsistent, and how to measure inconsistency and improve the judgments, when possible to obtain better consistency is a concern of the AHP. The derived priority scales are synthesized by multiplying them by the priority of their parent nodes and adding for all such nodes.

To make a decision in an organized way to generate priorities we need to decompose the decision into the following steps [19]:

1) Define the problem and determine the kind of knowledge sought.

2) Structure the decision hierarchy from the top with the goal of the decision, then the objectives from a broad perspective, through the intermediate levels (criteria on which subsequent elements depend) to the lowest level (which usually is a set of the alternatives).

3) Construct a set of pairwise comparison matrices. Each element in an upper level is used to compare the elements in the level immediately below with respect to it.

4) Use the priorities obtained from the comparisons to weigh the priorities in the level immediately below. Do this for every element. Then for each element in the level below add its weighed values and obtain its overall or global priority. Continue this process of weighing and adding until the final priorities of the alternatives in the bottom most level are obtained.

\section{Goal Programming (GP)}

GP is an important technique for allowing DMs to consider several objectives in finding a set of acceptable solutions. This technique is modification and extension of linear programming. Linear programming deals with only one single objective to be minimized or maximized, and subject to some constraint; it, therefore, has limitations in solving a problem with multiple objectives. Goal programming, instead, can be used as an effective approach to handle a decision concerning multiple and conflicting goals. The goal-programming approach is extensively applied in decision analysis in operations research. [20].

GP is used with combination of other decision making methods such as AHP in which AHP provides an input for GP. Integrated AHP-GP is applied in many fields such as reliability engineering [21], assembly line selection [22], capital budgeting [23], location selection [24].

\section{PRoposed Methodology}

In proposed methodology AHP method is used to compare alternative concepts for each product component based on life cycle design attributes. Also components are compared to each other to extract their importance weight. Then GP technique is applied on output of AHP to find the best alternative concept in order to optimize the objectives and satisfy the constraints. This section describes each step of the proposed methodology in detail.

\section{A. Product Description}

The first step in the methodology is the functional and physical decomposition analyses of a product or system. The decomposition process helps in mapping out a relationship between the product functionalities and its physical components. At the end of the physical decomposition analysis, a list of basic components, $C=\left\{C_{1}, \ldots, C_{i}, \ldots C_{I}\right\}$, is identified.

\section{B. Identify Possible Candidate Concepts}

For each basic component identified in previous step, identify possible candidate concepts $T=\left\{T_{1}, \ldots, T_{j}, \ldots T_{J}\right\}$.

\section{Identify Evaluation Criteria}

The next step is to identify key attributes of interest or design objectives of concept selection. Let $A=\left\{A_{1}, \ldots, A_{k}, \ldots A_{K}\right\}$ be the list of attributes. It is suggested to use performance, marketing, maintenance, manufacturing capability, safety, environment as evaluation attributes.

\section{Identify the Appropriate Linguistic Variables}

In this step, appropriate linguistic scales should be defined. These scales will be used to compare concept alternatives and components with respect to each attribute. These linguistic scales can be expressed in positive triangular fuzzy numbers, as shown in Table I and in Fig. 1.

\section{E. Cost Evaluation}

In this phase each component should be evaluated regarding available concept alternatives to see what would be an approximate cost effect if the component built with that concept

\section{F. Determine Cost and Budget Constraints}

In product design, there are some constraints regarding concepts that should be considered. Some concepts may be in contradiction with each other. Also we need to define our budget limits in this step.

\begin{tabular}{|c|c|c|}
\hline Lingustic Scale & $\begin{array}{l}\text { Triangular } \\
\text { Fuzzy Scale }\end{array}$ & $\begin{array}{l}\text { Triangular Fuzzy } \\
\text { Reciprocal Scale }\end{array}$ \\
\hline Just Equal (JE) & $(1,1,1)$ & $(1,1,1)$ \\
\hline Equally Preferred (EP) & $(1,1,3)$ & $(1 / 3,1,1)$ \\
\hline Moderately Preferred (MP) & $(1,3,5)$ & $(1 / 5,1 / 3,1)$ \\
\hline Strongly Preferred (SP) & $(3,5,7)$ & $(1 / 7,1 / 5,1 / 3)$ \\
\hline Very Strongly Preferred (VS) & $(5,7,9)$ & $(1 / 9,1 / 7,1 / 5)$ \\
\hline Extremely Preferred (EX) & $(7,9,9)$ & $(1 / 9,1 / 9,1 / 7)$ \\
\hline
\end{tabular}

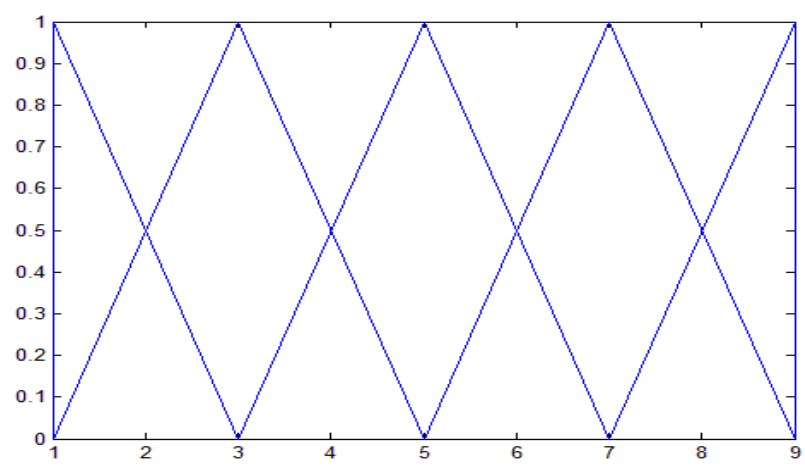

Fig. 1. The numerical approximation system for tangible factors 
TABLE II: ALTERNATIVE CONCEPTS COMPARISON FOR COMPONENT 1

\begin{tabular}{|c|c|c|c|c|c|c|c|c|c|c|c|c|c|c|c|c|c|c|c|c|c|c|c|c|}
\hline \multirow{2}{*}{$\begin{array}{l}\text { Alternatice } \\
\text { concepts }\end{array}$} & \multicolumn{4}{|c|}{ A1 } & \multicolumn{4}{|c|}{ A2 } & \multicolumn{4}{|c|}{ A3 } & \multicolumn{4}{|c|}{ A4 } & \multicolumn{4}{|c|}{ A5 } & \multicolumn{4}{|c|}{ A6 } \\
\hline & C1 & C2 & C3 & C4 & C1 & C2 & C3 & C4 & C1 & $\mathrm{C} 2$ & C3 & C4 & C1 & $\mathrm{C} 2$ & C3 & C4 & C1 & $\mathrm{C} 2$ & C3 & C4 & C1 & $\mathrm{C} 2$ & C3 & C4 \\
\hline $\mathrm{C} 1$ & JE & $\mathrm{MP}$ & VS & SP & JE & MP- & SP- & MP- & $\mathrm{JE}$ & SP & EX & EX & $\mathrm{JE}$ & EP & EP- & MP- & JE & EP & $\mathrm{MP}$ & $\mathrm{MP}$ & $\mathrm{JE}$ & EP & SP- & SP- \\
\hline $\mathrm{C} 2$ & - & JE & SP & SP & - & JE & MP- & MP- & - & $\mathrm{JE}$ & VS & vs & - & $\mathrm{JE}$ & EP- & MP- & - & $\mathrm{JE}$ & $\mathrm{MP}$ & $\mathrm{MP}$ & - & $\mathrm{JE}$ & SP- & SP- \\
\hline C3 & - & - & $\mathrm{JE}$ & EP & - & - & $\mathrm{JE}$ & MP- & - & - & $\mathrm{JE}$ & $\mathrm{MP}$ & - & - & $\mathrm{JE}$ & MP- & - & - & $\mathrm{JE}$ & $\mathrm{JE}$ & - & - & $\mathrm{JE}$ & $\mathrm{JE}$ \\
\hline C4 & - & - & - & $\mathrm{JE}$ & - & - & - & $\mathrm{JE}$ & - & - & - & $\mathrm{JE}$ & - & - & - & JE & - & - & - & $\mathrm{JE}$ & - & - & - & $\mathrm{JE}$ \\
\hline Weight & 0.51 & 0.44 & 0.06 & 0.00 & 0.01 & 0.23 & 0.37 & 0.39 & 0.66 & 0.35 & 0.00 & 0.00 & 0.20 & 0.13 & 0.25 & 0.42 & 0.40 & 0.40 & 0.10 & 0.10 & 0.04 & 0.00 & 0.48 & 0.48 \\
\hline
\end{tabular}

TABLE III: ALTERNATIVE CONCEPTS COMPARISON FOR COMPONENT 2

\begin{tabular}{|c|c|c|c|c|c|c|c|c|c|c|c|c|}
\hline \multirow{2}{*}{$\begin{array}{l}\text { Alternatice } \\
\text { concepts }\end{array}$} & \multicolumn{2}{|c|}{ A 1} & \multicolumn{2}{|c|}{ A 2} & \multicolumn{2}{|c|}{ A3 } & \multicolumn{2}{|c|}{ A4 } & \multicolumn{2}{|c|}{ A 5} & \multicolumn{2}{|c|}{ A 6} \\
\hline & C 5 & C6 & C5 & C6 & C5 & C6 & C 5 & C6 & C5 & C6 & C 5 & C 6 \\
\hline C 5 & $\mathrm{JE}$ & MP- & $\mathrm{JE}$ & $\mathrm{MP}$ & $\mathrm{JE}$ & EP- & $\mathrm{JE}$ & MP & $\mathrm{JE}$ & EP & $\mathrm{JE}$ & VS \\
\hline C 6 & - & JE & - & JE & - & JE & - & JE & - & $J E$ & - & $\mathrm{JE}$ \\
\hline Weight & 0.161 & 0.839 & 0.839 & 0.161 & 0.5 & 0.5 & 0.839 & 0.161 & 0.5 & 0.5 & 1 & 0 \\
\hline
\end{tabular}

\begin{tabular}{|c|c|c|c|c|c|c|c|c|c|c|c|c|}
\hline \multirow{2}{*}{$\begin{array}{l}\text { Alternatice } \\
\text { concepts }\end{array}$} & \multicolumn{2}{|c|}{ A 1} & \multicolumn{2}{|c|}{ A 2} & \multicolumn{2}{|c|}{ A3 } & \multicolumn{2}{|c|}{ A4 } & \multicolumn{2}{|c|}{ A 5} & \multicolumn{2}{|c|}{ A 6} \\
\hline & C 7 & C 8 & $C 7$ & C 8 & C 7 & C 8 & C 7 & C 8 & $C 7$ & C 8 & $C 7$ & C 8 \\
\hline C 7 & $\mathrm{JE}$ & VS & $\mathrm{JE}$ & VS- & $\mathrm{JE}$ & EP & $\mathrm{JE}$ & SP & $\mathrm{JE}$ & $\mathrm{JE}$ & $\mathrm{JE}$ & MP- \\
\hline $\mathrm{C} 8$ & - & JE & - & JE & - & JE & - & JE & - & JE & - & JE \\
\hline Weight & 1 & 0 & 0 & 1 & 0.5 & 0.5 & 1 & 0 & 0.5 & 0.5 & 0.161 & 0.839 \\
\hline
\end{tabular}

\begin{tabular}{|c|c|c|c|c|c|c|c|c|c|c|c|c|c|c|c|c|c|c|}
\hline \multirow{2}{*}{ Components } & \multicolumn{3}{|c|}{ A 1} & \multicolumn{3}{|c|}{ A 2} & \multicolumn{3}{|c|}{$\mathrm{A} 3$} & \multicolumn{3}{|c|}{ A 4} & \multicolumn{3}{|c|}{ A 5} & \multicolumn{3}{|c|}{ A 6} \\
\hline & Comp1 & Comp2 & Сomp3 & Comp1 & Comp2 & Comp3 & Comp1 & Comp2 & Comp3 & Comp1 & Comp2 & Comp3 & Comp1 & Comp2 & Comp3 & Comp1 & Comp2 & Comp3 \\
\hline Comp1 & JE & MP- & SP- & JE & SP- & VS- & JE & MP & MP- & JE & SP & SP & JE & VS & VS & JE & SP & MP \\
\hline Comp2 & - & $\mathrm{JE}$ & MP- & - & JE & $\mathrm{MP}$ & - & JE & SP & - & JE & MP & - & JE & EP & - & $\mathrm{JE}$ & MP \\
\hline Comp3 & - & - & JE & - & - & JE & - & - & JE & - & - & JE & - & - & JE & - & - & JE \\
\hline Weight & 0.00 & 0.36 & 0.64 & 0.00 & 0.52 & 0.48 & 0.30 & 0.40 & 0.30 & 0.72 & 0.28 & 0.00 & 1.00 & 0.00 & 0.00 & 0.73 & 0.27 & 0.00 \\
\hline
\end{tabular}

TABLE VI: ESTIMATED COST FOR BUILDING COMPONENTS WITH RESPECT TO CONCEPTS

\begin{tabular}{|c|c|c|c|c|c|c|c|c|}
\hline Components & $\mathrm{C} 1$ & $\mathrm{C} 2$ & $\mathrm{C} 3$ & $\mathrm{C} 4$ & $\mathrm{C} 5$ & C6 & $\mathrm{C7}$ & $\mathrm{C} 8$ \\
\hline Comp2 & - & - & - & - & $\$ 50 K$ & $\$ 100 K$ & - & - \\
\hline Comp3 & - & - & - & - & - & - & $\$ 20 K$ & $\$ 40 K$ \\
\hline
\end{tabular}

TABLE VII: ASPIRATION LEVELS

\begin{tabular}{c|cccccc} 
Goals & $\mathrm{A}_{1}$ & $\mathrm{~A}_{2}$ & $\mathrm{~A}_{3}$ & $\mathrm{~A}_{4}$ & $\mathrm{~A}_{5}$ & $\mathrm{~A}_{6}$ \\
\hline Aspiration level & 0.94185 & 0.91700 & 0.54710 & 0.41199 & 0.40470 & 0.62136
\end{tabular}

\section{G. Concept Selection Using a Multi-Objective Optimization Model}

Individual optimization models are run for each of the attributes (criteria), namely, performance, manufacturing capability, Marketing, Maintenance, safety and environment. Design and budget constraints should be considered. The details of the mathematical model are the following:

$$
\operatorname{Max}_{K} \sum_{i} \sum_{j} W_{i, k} P_{j, k} X_{i, j} \quad \forall k
$$

Subject to:

$$
\begin{aligned}
& \sum_{j} X_{i, j}=1 \quad \forall i \\
& \sum_{i} \sum_{j} E_{i, j} X_{i, j} \leq B
\end{aligned}
$$

where,

$$
i=1 \text { Index for Component }
$$

$j=1$ Index for Concept

$k=1$ Index for Attributes

$Z_{k}=1$ Objective function for $k^{\text {th }}$ problem

$W_{i, k}$ Importance weight of component $i$ with respect to attribute $k$

$p_{i, k}$ Performance index for concept $i$ with respect to attribute $k$

$X_{i, k}$ Decision variable, equals 1 if component $i$ is built with concept $j$, otherwise 0

$E_{i, j}$ Estimated cost of building component $i$ with concept $j$ 


\section{H. Available Budget}

Constraint (1) guarantees a concept be assigned to each component. Constraint (2) ensures that our assignment will not exceed budget limit. Also depending on situation, necessary design constraints should be added to the model.

\begin{tabular}{l|c}
\multicolumn{2}{l}{ TABLE VIII: SELECTED CONCEPTS } \\
Component & Selected concept \\
\hline Component 1 & Concept 1 \\
Component 2 & Concept 5 \\
Component 3 & Concept 7
\end{tabular}

The objective function values $\left(Z_{k}\right)$ of each model determines the aspiration levels $\left(A_{k}\right)$ for the goal program to be run. We use the goal programming (GP) model for optimizing contrasting objectives, maximization of performance, manufacturing capability, Marketing, Maintenance, safety and environment.

We define $d$ as the worst deviation from design goals. The details of the mathematical model will be as follows:

$$
\operatorname{Min} d
$$

Subject to:

$$
\begin{gathered}
\sum_{i} \sum_{j} W_{i, k} P_{j, k} X_{i, j}+d \geq A_{k} \quad \forall k \\
\sum_{j} X_{i, j}=1 \quad \forall i \\
\sum_{i} \sum_{j} E_{i, j} X_{i, j} \leq B
\end{gathered}
$$

where,

$d$ Objective function, the worst deviation from design goals

$A_{k}$ aspiration levels for $k_{t h}$ objective

\section{ILLUSTRATIVE EXAMPLE}

Company $\mathrm{X}$ is a leader company in medical devices. This company is planning to develop new product for the next five years to retain its industry leadership. After the functional and physical decomposition analyses of the product 3 main components are identified. There are 8 alternative concepts available, 4 concepts for the first component, and 2 concepts for both second and third components. The company desires to evaluate and select the best concept regarding to 6 life cycle design goals ( $\left.A_{1}, A_{2} A_{3}, A_{4} A_{5}, A_{6}\right)$. Linguistic scales proposed in are used for pairwise comparisons. Table II, Table III and Table IV are respectively showing the results for pairwise comparisons regarding different design goals. Fuzzy AHP method is applied to obtain weights $\left(P_{j, k}\right)$.

Product components are also compared to each other with respect to design goals and weights $\left(W_{i, k}\right)$ are identified by applying fuzzy AHP method. Results are shown in Table V.

Estimated cost for building components with respect to concepts are shown in Table VI. The budget limit is estimated \$300K.

Table VII shows the obtained aspiration levels $\left(Z_{k}\right)$ after the first running of model.

After re-running the model, the worst deviation from design goals will be $d=0.4845$ and final results are shown in Table VIII.

\section{CONCLUSION}

Selection of a proper concept is one of the most important and strategic tasks that should have been taken in early stages of new product development. In this process product life cycle issues should be taken into account. In this paper, a hybrid methodology based on FAHP and Goal programming is proposed for this problem. At first stage fuzzy AHP is used to overcome adhered uncertainty in design goals and attributes and obtain the importance weights. Then using Goal programming techniques enables us to maximize design objectives and simultaneously considering design and budget constraints.

\section{REFERENCES}

[1] G. E. Okudan and S. Tauhid, "Concept selection methods \& ndash; a literature review from 1980 to 2008," International Journal of Design Engineering, vol. 1, pp. 243-277, 2008.

[2] J. L. Nevins, D. E. Whitney, and T. L. De Fazio, Concurrent Design of Products and Processes: A Strategy for the Next Generation in Manufacturing, New York: McGraw-Hill, 1989.

[3] J. Wang, "A fuzzy outranking method for conceptual design evaluation," International Journal of Production Research, vol. 35, pp. 995-1010, 1997.

[4] S. Pugh, "Concept selection - a method that works," presented at the International Conference of Engineering Design, 1995.

[5] R. Y. Fung, Y. Chen, and J. Tang, "A quality-engineering-based approach for conceptual product design," The International Journal of Advanced Manufacturing Technology, vol. 32, pp. 1064-1073, 2007.

[6] E. Marsh, Hierarchical Decision Making in Machine Design, Ed, 1993.

[7] A. M. King and S. Sivaloganathan, "Development of a methodology for concept selection in flexible design strategies," Journal of Engineering Design, vol. 10, pp. 329-349, 1999/12/01 1999.

[8] G. E. Okudan and R. A. Shirwaiker, "A multi-stage problem formulation for concept selection for improved product design," in Technology Management for the Global Future, PICMET 2006, 2006 pp. 2528-2538.

[9] D. Y. Chang, "Applications of the extent analysis method on fuzzy AHP," European Journal of Operational Research, vol. 95, pp. 649-655, 1996.

[10] Z. Ayag, "An integrated approach to evaluating conceptual design alternatives in a new product development environment," International Journal of Production Research, vol. 43, pp. 687-713, 2005/02/15 2005.

[11] P. Fitch and J. S. Cooper, "Life-cycle modeling for adaptive and variant design. Part 1: Methodology," Research in Engineering Design, vol. 15 , pp. 216-228,2005

[12] Y. Umeda, "Study on life-cycle design for the post mass production paradigm," Artificial Intelligence for Engineering Design, Analysis and Manufacturing, vol. 14, p. 149, 2000.

[13] E. Regnier and W. F. Hoffman, III, "Uncertainty model for product environmental performance scoring," in Proc. the 1998 IEEE International Symposium on, pp. 207-212, 1998.

[14] J. L. Eisenhard, "Approximate life-cycle assessment in conceptual product design," Journal of Industrial Ecology, vol. 4, p. 61, 2000.

[15] A. Azapagic and R. Clift, "Life cycle assessment and multiobjective optimisation," Journal of Cleaner Production, vol. 7, pp. 135-143, 1999.

[16] A. Anand and M. F. Wani, "Product Life-Cycle modeling and evaluation at the conceptual design stage: A digraph and matrix approach," Journal of Mechanical Design, vol. 132, pp. 091010-9, 2010 .

[17] L. A. Zadeh, "Fuzzy sets," Information and Control, vol. 8, pp. 338-353, 1965. 
[18] R. E. Bellman and L. A. Zadeh, "Decision-Making in a Fuzzy Environment," Management Science, vol. 17, pp. B-141-164, December 1, 1970.

[19] T. L. Saaty, "Decision making with the analytic hierarchy process," Int. J. Services Sciences, vol. 1, pp. 83-98, 2008.

[20] M. Bertolini and M. Bevilacqua, "A combined goal programming-AHP approach to maintenance selection problem," Reliability Engineering \& System Safety, vol. 91, pp. 839-848, 2006.

[21] N. Arunraj and J. Maiti, "Risk-based maintenance policy selection using AHP and goal programming," Safety Science, vol. 48, pp. $238-247,2010$

[22] A. G. Zeki and R. G. Özdemir, "A combined fuzzy AHP-goal programming approach to assembly-line selection," Journal of Intelligent and Fuzzy Systems, vol. 18, pp. 345-362, 01/01/ 2007.

[23] Y. C. Tang and C. T. Chang, "Multicriteria decision-making based on goal programming and fuzzy analytic hierarchy process: An application to capital budgeting problem," Knowledge-Based Systems, vol. 26, pp. 288-293, 2// 2012.

[24] S. Zahir and R. Sarker, "Optimising multi-objective location decisions in a supply chain using an AHP-enhanced goal-programming model,"
International Journal of Logistics Systems and Management, vol. 6, pp. 249-266, 2010

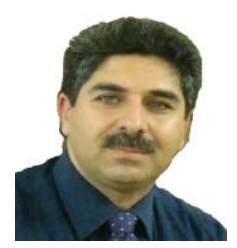

Alireza Yazdankhah received the B.S. and M.S. in industrial and systems engineering and currently doing his $\mathrm{PhD}$. He is a faculty member in the Islamic Azad University - Bonab Branch, College of Engineering, Bonab, Iran. He is also the chair of the Department of Industrial and Systems Engineering. His research area is systems design and optimization and has done many consulting project in industry.

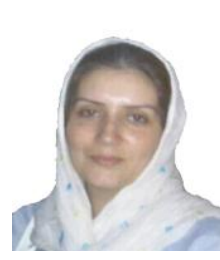

Mojgan Fathalipourbonab graduated in physics. She is the head of R\& D department at Arkan Trailer Bonab, Bonab, Iran. 